\title{
SAVIANI, Dermeval. Pedagogia histórico-crítica: primeiras aproximações. 11. ed. rev. Campinas: Autores Associados, 2011. 137 p.
}

\author{
Daniele Ditzel Mattioli*
}

Os estudos e discussões acerca das teorias da educação possuem um caráter significativo para o campo educacional, uma vez que apenas a ação educativa consciente é capaz de formar cidadãos críticos. Nesse sentido, a opção por uma teoria implica em assumir os seus pressupostos de forma a ser imprescindível uma prática educativa responsável, sustentada no conhecimento teórico.

Dermeval Saviani, professor emérito da UNICAMP e coordenador geral do grupo de pesquisa "História, Sociedade e Educação no Brasil - HISTEDBR", é o precursor de um trabalho de análise sobre as teorias da educação que pretende ir além da crítica ao modelo educacional que favorece a manutenção de uma sociedade pautada no capital para buscar alternativas para a transformação da sociedade. A obra Pedagogia histórico-crítica: primeiras aproximações, $11^{\mathrm{a}}$ edição revista, publicada em 2011 discute o caminho percorrido pelo autor na elaboração de uma tendência pedagógica crítica, pautada no materialismo histórico de forma a "compreender a questão educacional com base no desenvolvimento histórico objetivo" (SAVIANI, 2011, p. 76).

A primeira publicação data de 1991, o que demonstra a relevância da obra. No prefácio desta última edição, Saviani destaca a realização do Seminário "Pedagogia histórico-crítica: 30 anos", ocorrido em dezembro de 2009 na UNESP, campus de Araraquara. O evento contou com a participação de professores e estudiosos da educação que desenvolveram suas pesquisas a partir da pedagogia histórico-crítica, entre os quais podemos citar: Newton Duarte, Sandra Soares Della Fonte, Lígia Márcia Martins, Marilda Gonçalves Dias Facci, Lidiane T. B. Mazzeu, entre outros. A palestra de encerramento ficou a cargo do professor Saviani que apresentou os antecedentes que levaram à elaboração da pedagogia histórico-crítica.

$\mathrm{Na}$ introdução denominada Escola e Saber Objetivo na Perspectiva HistóricoCrítica o autor retoma a obra Escola e democracia de forma que os textos encontrados

\footnotetext{
* Mestre em Educação pelo PPGE da Universidade Estadual de Ponta Grossa. Professora da Rede Estadual de Ensino do Estado do Paraná. E-mail: <mattiolidd@yahoo.com.br>
} 
no presente livro seguem com as análises iniciadas anteriormente. Aponta de forma sintética o conteúdo da obra que passa por uma

[...] síntese das principais teorias da educação, abrangendo as teorias não críticas (pedagogia tradicional, pedagogia nova e pedagogia tecnicista) e as teorias crítico-reprodutivistas (teoria da escola enquanto violência simbólica, teoria da escola enquanto aparelho ideológico de Estado e teoria da escola dualista). (SAVIANI, 2011, p. 5).

O capítulo denominado Escola e democracia I - A teoria da curvatura da vara é considerado preliminar para a pedagogia histórico-crítica, pois "a perspectiva historicizadora aí adotada constitui uma exigência metodológica inerente à concepção histórico-crítica" (SAVIANI, 2011, p. 6).

A presente obra inicia com a discussão que encerra Escola e democracia sobre "à natureza e especificidade da educação" (SAVIANI, 2011, p. 6), sendo o "trabalho não material" a categoria na qual se encontra a natureza da educação.

O livro está organizado em seis capítulos que discorrem acerca da fundamentação da pedagogia histórico-crítica, tendência gestada na década de 1980, como possível caminho para superação das tendências não críticas e crítico-reprodutivistas da educação.

O capítulo 1 discorre Sobre a natureza e a especificidade da educação partindo do entendimento da educação como fenômeno específico do ser humano e que, portanto, apenas será possível compreender a natureza da educação tendo como referencial a natureza humana. Merece destaque neste capítulo a recuperação do conceito de clássico visto ser "aquilo que se firmou como fundamental, como essencial. Pode, pois, constituir-se num critério útil para a seleção dos conteúdos do trabalho pedagógico" (SAVIANI, 2011, p. 13) e, nesse sentido fica claro que a atuação docente fundamentada nestes saberes conduz ao conhecimento necessário para uma formação crítica. Esta observação é relevante, pois percebe-se no espaço educacional uma tendência a confundir o trabalho educativo sustentado em conteúdos socialmente significativos com a prática tradicional, e desta forma, a utilização de novas metodologias e recursos por professores sem a devida fundamentação teórica sobrecarregam as escolas de práticas educativas improvisadas.

Outra contribuição importante está no resgate do papel da escola enquanto instituição que tem como principal função a socialização do saber sistematizado. Este posicionamento quanto ao papel da escola reforça uma das ideias chave da pedagogia histórico-crítica de que apenas através do conhecimento historicamente acumulado é possível a análise crítica da realidade com vistas a uma ação transformadora. 
Para tanto, o autor apresenta sua noção de currículo como "o conjunto das atividades nucleares desenvolvidas pela escola” (SAVIANI, 2011, p. 15), isto porque, percebe-se um movimento nas escolas da ampliação de atividades a serem absorvidas pelo currículo escolar de forma que o saber elaborado acaba em segundo plano, situação esta que descaracteriza a ação escolar. Isto posto, acaba por ser verificar um inchaço das atividades escolares o que dificulta, se não inviabiliza uma ação formadora no sentido da luta pela transformação social.

No capítulo seguinte Competência política e compromisso técnico lo pomo da discórdia e o fruto proibido), Saviani se posiciona diante da polêmica gerada pelo livro Magistério de $1^{\circ}$ grau: da competência técnica ao compromisso político, de Guiomar Namo de Mello. Sua manifestação foi estimulada após a publicação do artigo de Paolo Nosella, O compromisso político como horizonte da competência técnica, com o intuito de "desfazer uma imagem equivocada que, por vezes, os artigos polêmicos provocam nos leitores: a ideia de que o autor da crítica desautoriza o autor criticado" (SAVIANI, 2011, p. 21).

Este capítulo está dividido em três partes, onde Saviani inicia com uma explanação sobre o texto da Guiomar de forma a afastar, como ele chama, as críticas apressadas sofridas pela autora. A tese defendida no livro em questão sugere "que a passagem do senso comum à vontade política se dá pela mediação da competência técnica" (SAVIANI, 2011, p. 24) e está justamente na expressão competência técnica a origem da polêmica. No entanto, Saviani demonstra que as críticas dirigidas à Guiomar N. de Mello são superficiais, uma vez que a autora deixa claro na obra o seu entendimento sobre o que considera competência técnica, pois esta "compreende o domínio teórico e prático dos princípios e conhecimentos que regem a instituição escolar" (SAVIANI, 2011, p. 26). Dito isto, não é possível aproximar a competência técnica defendida por Guiomar da postura tecnicista como o fizeram os críticos da obra tendo em vista que "a competência técnica é um momento do compromisso político" (SAVIANI, 2011, p. 31, grifo do autor).

Sobre o artigo de Nosella, Saviani destaca que para o autor o compromisso político é o "ponto crítico do processo educativo" (SAVIANI, 2011, p. 40), visto como um horizonte ainda a ser atingido e desta forma, é enfático na necessidade do aprofundamento das reflexões críticas. $\mathrm{O}$ autor ainda persevera "em afirmar a primazia do compromisso político, ao qual subordina de modo insistente, a competência técnica" (SAVIANI, 2011, p. 43) de forma que, "para ele, o horizonte político determina a qualidade, o sinal (positivo ou negativo), o sentido e o conteúdo da competência técnica" (SAVIANI, 2011, p. 43).

Entende Saviani que a discussão parte do conceito de mediação, presente nas duas obras, tratado de forma explícita por Guiomar e insinuado por Nosella que, de certo modo, admite "que é pela competência técnica que se realiza o 
compromisso político" (SAVIANI, 2011, p. 44) ao "dizer que o saber-fazer é concretização de uma linha política e que é no saber-fazer que se concretizam certas intenções sociais gerais" (SAVIANI, 2011, p. 44).

Ao fim da análise, Saviani entende que a divergência encontra-se sobre os conceitos utilizados pelos autores, o de "saber escolar" por Guiomar e de "concepção histórico-proletária de cultura" por Nosella, ambos pouco explorados.

A busca pela aproximação dos textos divergentes seguiu pela compreensão do saber objetivo como algo distinto de neutralidade de forma a se perceber "que não existe conhecimento desinteressado; portanto, a neutralidade é impossível. Entretanto, o caráter sempre interessado do conhecimento não significa a impossibilidade da objetividade" (SAVIANI, 2011, p. 50).

Saviani conclui pela necessidade da competência técnico-política na defesa do compromisso político em educação, visto que "a identificação dos fins implica imediatamente competência política e mediatamente competência técnica; a elaboração dos métodos para atingi-los implica, por sua vez, imediatamente competência técnica e mediatamente competência política" (SAVIANI, 2011, p. 55).

Denominado A pedagogia histórico-crítica no quadro das tendências críticas da Educação Brasileira, o capítulo 3 contextualiza o momento em que surge a tendência pedagógica, bem como busca esclarecer as críticas a ela dirigidas. Verificado o limite da teoria crítico-reprodutivista, fruto da revolução cultural de 1968, a discussão entre os educadores passou a buscar meios para "atuar de modo crítico no campo pedagógico, como ser um professor que, ao agir, desenvolve uma prática de caráter crítico" (SAVIANI, 2011, p. 59). É nesse contexto que Saviani passa a aplicar a dialética nas questões educacionais de forma a ter como fundamento para o trabalho pedagógico a perspectiva histórica.

O capítulo 4, A pedagogia bistórico-crítica e a educação escolar, apresenta esta tendência no quadro da história da educação brasileira, bem como seu sentido básico que "envolve a necessidade de se compreender a educação no seu desenvolvimento histórico-objetivo e, por consequência, a possibilidade de se articular uma proposta pedagógica cujo ponto de referência, cujo compromisso, seja a transformação da sociedade e não sua manutenção, a sua perpetuação" (SAVIANI, 2011, p. 80).

Apresenta a defesa do que considera como função específica da escola que á a socialização do saber socialmente elaborado e o valor do trabalho escolar como elemento indispensável ao desenvolvimento cultural.

A materialidade da ação pedagógica e os desafios da pedagogia bistórico-crítica são discutidas no capítulo 5 , de forma a considerar que o fundamento e a finalidade da teoria estão na prática. Nesse sentido, “a prática será tanto mais coerente 
e consistente, será tanto mais qualitativa, será tanto mais desenvolvida quanto mais consistente e desenvolvida for a teoria que a embasa" (SAVIANI, 2011, p. 91). Os desafios apresentados dizem respeito à ausência de um sistema nacional de educação, o que resulta em uma situação de precariedade educacional com a verificação do alto índice de analfabetismo no país.

Outra questão importante diz respeito ao orçamento destinado à educação, visto que os recursos definidos pela Constituição Federal são, por vezes, "desviados" para serviços complementares à ação educativa como merenda e transporte que deveriam sair das respectivas pastas. A questão organizacional das escolas é apontada como um entrave para o desenvolvimento das atividades, pois ainda mantém a estrutura pensada no período ditatorial. Por fim, coloca a questão da descontinuidade alertando que as políticas educacionais devem ser pensadas para o médio e longo prazo uma vez que "o trabalho educativo tem que se desenvolver num tempo suficiente para que as habilidades, os conceitos que se pretende sejam assimilados pelos alunos, de fato, se convertam numa espécie de segunda natureza" (SAVIANI, 2011, p. 107). Desta forma, as políticas públicas educacionais devem ser pensadas enquanto propostas de Estado e não limitadas ao tempo dos governos, uma vez que o processo para a sua completa implementação exige mudanças complexas, que incidirão nas estruturas estabelecidas.

No último capítulo é apresentada a Contextualização histórica e teórica da pedagogia histórico-crítica que remonta a década de 1970 com a crítica às teorias da educação que não possibilitavam pensar a ação educativa de modo a transformar a sociedade. Vislumbrou-se então "uma proposta pedagógica que estivesse atenta aos determinantes sociais da educação e que permitisse articular o trabalho pedagógico com as relações sociais" (SAVIANI, 2011, p. 118). No tocante a nomenclatura histórico-crítica, Saviani explica que ela traduz "a apreensão do movimento histórico que se desenvolve dialeticamente em suas contradições" (SAVIANI, 2011, p. 119) sendo exatamente o que se busca, uma teoria crítica fundamentada na história.

Com relação ao fundamento teórico é indiscutível a contribuição de Marx, por se tratar de uma "dialética histórica expressa no materialismo histórico" (SAVIANI, 2011, p. 120). Outros autores também influenciaram esta pedagogia como Sánchez Vásquez a partir do qual foi elaborado o conceito de práxis, sendo esta "uma prática fundamentada teoricamente" (SAVIANI, 2011, p. 120). Ainda podemos citar como referências para a pedagogia histórico-crítica autores que desenvolveram suas discussões também com base no materialismo histórico, além de Marx e Gramsci, Suchodolski; Manacorda; Snyders.

A pedagogia histórico-crítica considera a educação como “o ato de produzir, direta e intencionalmente, em cada indivíduo singular, a humanidade 
que é produzida histórica e coletivamente pelo conjunto dos homens" (SAVIANI, 2011, p. 13). Sua construção, ainda em processo, representa um avanço para o campo educacional brasileiro por sustentar que apenas mediante o domínio do conhecimento socialmente produzido será viabilizada a transformação social com a eliminação dos privilégios existentes e a efetiva concretização dos princípios democráticos. 